\title{
Antibodies to myelin oligodendrocyte glycoprotein in bilateral and recurrent optic neuritis
}

\section{OPEN}

Sudarshini Ramanathan,

FRACP

Stephen W. Reddel,

FRACP, PhD

Andrew Henderson,

FRACP, PhD

John D.E. Parratt,

FRACP, MD

Michael Barnett, FRACP,

$\mathrm{PhD}$

Prudence N. Gatt, MSc

Vera Merheb, BSc

Raani-Yogeeta Anusuiya

Kumaran, BMedSc

Karrnan Pathmanandavel, MBBS

Nese Sinmaz, BSc

Mahtab Ghadiri, MBBS

Con Yiannikas, FRACP

Steve Vucic, FRACP,

$\mathrm{PhD}$

Graeme Stewart, FRACP,

$\mathrm{PhD}$

Andrew F. Bleasel,

FRACP, PhD

David Booth, PhD

Victor S.C. Fung,

FRACP, PhD

Russell C. Dale, PhD

Fabienne Brilot, $\mathrm{PhD}$

Correspondence to

Dr. Brilot:

Fabienne.brilot@sydney.edu.au

Supplemental data at Neurology.org/nn

\section{ABSTRACT}

Objective: We examined a cohort of adults with aquaporin-4 (AQP4) antibody-negative neuromyelitis optica/neuromyelitis optica spectrum disorder (NMO/NMOSD) for antibodies to myelin oligodendrocyte glycoprotein (MOG).

Methods: We performed a flow cytometry cell-based assay using live human lentivirus-transduced cells expressing full-length surface MOG. Serum was tested in 23 AQP4 antibody-negative NMO/NMOSD patients with bilateral and/or recurrent optic neuritis (BON, $n=11$ ), longitudinally extensive transverse myelitis (LETM, $n=10$ ), and sequential BON and LETM $(n=2)$, as well as in patients with multiple sclerosis (MS, $n=76)$ and controls $(n=52)$.

Results: MOG antibodies were detected in 9/23 AQP4 antibody-negative patients with NMO/ NMOSD, compared to 1/76 patients with MS and 0/52 controls $(p<0.001)$. MOG antibodies were detected in 8/11 patients with BON, 0/10 patients with LETM, and 1/2 patients with sequential BON and LETM. Six of 9 MOG antibody-positive patients had a relapsing course. MOG antibody-positive patients had prominent optic disc swelling and were more likely to have a rapid response to steroid therapy and relapse on steroid cessation than MOG antibody-negative patients ( $p=0.034$ and $p=0.029$, respectively). While 8/9 MOG antibody-positive patients had good follow-up visual acuity, one experienced sustained visual impairment, 3 had retinal nerve fiber layer thinning, and one had residual spinal disability.

Conclusions: MOG antibodies have a strong association with BON and may be a useful clinical biomarker. MOG antibody-associated BON is a relapsing disorder that is frequently steroid responsive and often steroid dependent. Failure to recognize the disorder early and institute immunotherapy promptly may be associated with sustained impairment.

Classification of evidence: This study provides Class II evidence that MOG antibodies are associated with AQP4 antibody-negative BON (sensitivity 69\%, 95\% confidence interval [Cl] 42\%-87\%; specificity 99\%, 95\% Cl 93.7\%-99.8\%). Neurol Neuroimmunol Neuroinflamm 2014;1:e40; doi: 10.1212/NXI.0000000000000040

\section{GLOSSARY}

ADEM = acute disseminated encephalomyelitis; AQP4 = aquaporin-4; BON = bilateral and/or recurrent optic neuritis; $\mathbf{C l}=$ confidence interval; $\mathbf{C R I O N}=$ chronic relapsing inflammatory optic neuropathy; EDSS = Expanded Disability Status Scale; FACS = fluorescence-activated cell sorting; HEK293 = human embryonic kidney 293; Ig = immunoglobulin; LETM = longitudinally extensive transverse myelitis; $\mathbf{M D}=$ mean deviation; $\mathbf{M F I}=$ mean fluorescence intensity; $\mathbf{M O G}=$ myelin oligodendrocyte glycoprotein; $\mathbf{m R S}=$ modified Rankin Scale; $\mathbf{M S}=$ multiple sclerosis; NMO = neuromyelitis optica; NMOSD = neuromyelitis optica spectrum disorder; $\mathbf{O C T}=$ optical coherence tomography; $\mathbf{O N}=$ optic neuritis; RNFL = retinal nerve fiber layer; VFSS = visual functional system score.

Neuromyelitis optica (NMO) is a demyelinating disorder that preferentially affects the optic nerves and spinal cord and results in severe disability. ${ }^{1}$ The identification of immunoglobulin (Ig) G antibodies targeting aquaporin-4 (AQP4) in patients with NMO has distinguished this condition from multiple sclerosis (MS). ${ }^{1-3}$ The term NMO spectrum disorder (NMOSD) encompasses patients with more limited forms of NMO.,5 Despite the refinement of detection methods,

Authors' affiliations are listed at the end of the article.

Go to Neurology.org/nn for full disclosures. Funding information and disclosures deemed relevant by the authors, if any, are provided at the end of the article. The Article Processing Charge was paid by the authors.

This is an open access article distributed under the terms of the Creative Commons Attribution-Noncommercial No Derivative 3.0 License, which permits downloading and sharing the work provided it is properly cited. The work cannot be changed in any way or used commercially. 
$12 \%-30 \%$ of patients with NMO/NMOSD remain AQP4 antibody-negative. ${ }^{6-8}$ Investigating this cohort has important diagnostic and therapeutic implications.

Myelin oligodendrocyte glycoprotein (MOG) is a component of myelin and an antigen target in CNS demyelination. Immunization with MOG induces experimental autoimmune encephalitis, and MOG antibodies contribute to CNS demyelination in animal models. ${ }^{9-13}$ MOG is expressed by oligodendrocytes on the external surface of myelin, providing an accessible antigenic target for circulating autoantibodies.

Using cell-based assays, antibodies against native MOG have been identified in 20\%$40 \%$ of pediatric patients with acute disseminated encephalomyelitis (ADEM), optic neuritis $(\mathrm{ON})$, and relapsing demyelination disorders, including NMO/NMOSD. ${ }^{14-18}$ In contrast, the clinical relevance of MOG antibodies in adults is unclear, as only a minority of patients with MS and NMO/NMOSD are seropositive. ${ }^{16,18-24}$

Herein, we provide evidence that MOG antibodies are a clinical biomarker of bilateral and/ or recurrent optic neuritis (BON) in adults and describe the characteristic clinical course, response to therapy, and visual outcomes of this condition.

METHODS Patients and controls. Patients. We retrospectively investigated 23 patients who presented to neuroimmunology and neuro-ophthalmology clinics at 4 tertiary referral centers in Sydney, Australia (2004-2014) with AQP4 antibody-negative NMO/NMOSD (12 female; median age 38 years, range 17-59). These patients did not satisfy the $2010 \mathrm{McD}$ onald diagnostic criteria for MS. ${ }^{25}$ They presented with BON $(\mathrm{n}=11)$, longitudinally extensive transverse myelitis (LETM, $\mathrm{n}=10$ ), or sequential BON and LETM $(n=2)$. All patients with LETM had longitudinally extensive disease, with spinal cord involvement greater than 3 vertebral segments in length on MRI. The 2 patients with sequential BON and LETM satisfied the revised diagnostic criteria for $\mathrm{NMO}^{4}$ but were AQP4 antibody-negative. Nine of 11 patients with $\mathrm{BON}$ had simultaneous $\mathrm{BON}$ at least once, $+/-$ additional episodes of unilateral $\mathrm{ON}$, while $2 / 11$ had recurrent episodes of unilateral ON sequentially involving both eyes. In total, among the 11 patients with BON, there were $30 \mathrm{ON}$ episodes (18 unilateral and 12 simultaneous and bilateral). All 23 patients were negative for NMO-IgG antibodies tested by indirect immunofluorescence on monkey cerebrum, cerebellum, and stomach, and rat kidney, ${ }^{1,2}$ as well as for AQP4 antibodies by cell-based assay using the M23 isoform (Euroimmun, Lübeck, Germany). Twelve of 23 AQP4 antibody-negative patients with $\mathrm{NMO} /$ NMOSD had a relapsing presentation (6/11 BON, 4/10 LETM, 2/2 sequential BON and LETM). The relapses in the 6 patients with $\mathrm{BON}$ were either recurrent unilateral $\mathrm{ON}$ or $\mathrm{BON}$, while the 4 patients with LETM had only spinal relapses. The 2 patients with sequential BON and LETM had relapses involving both the optic nerves and spinal cord. The breakdown of diagnoses in all patients with BON and/or LETM who presented to the collaborating centers is presented in appendix e-1 at Neurology.org/nn.

Stored acute serum $\left(-80^{\circ} \mathrm{C}\right)$ taken during the first presentation $(\mathrm{n}=13)$, within 1 month of a relapse $(\mathrm{n}=5)$, or during remission $(n=5)$ was tested. The serum of $16 / 23$ patients was collected on no treatment. Of these, 9/16 patients had samples obtained at initial presentation, 3 within a month of an acute relapse, and 4 while in remission.

At sample collection, 4 patients had completed a course of pulsed steroids within the preceding 3 months, and 3 were experiencing relapses on long-term steroids and mycophenolate mofetil.

The AQP4 antibody-negative NMO/NMOSD cohort was investigated for infectious, inflammatory, and autoimmune differential diagnoses (tables e-1 and e-2). 3T MRI brain $(n=21)$ and whole spine $(\mathrm{n}=17)$ scans were reviewed by neuroradiologists. Steroid responsiveness was defined as a greater than $50 \%$ improvement in visual acuity or Expanded Disability Status Scale (EDSS) score within 24 hours of commencing IV (intravenous) steroids, and a relapse on steroid cessation was defined as acute worsening within 48 hours of cessation of IV steroids.

The sera of 76 patients with clinically definite MS as defined by the revised McDonald criteria ${ }^{25}$ were also tested ( 59 female; median age 43 years, range 22-71). These patients were classified as having relapsing-remitting $(n=68)$, secondary progressive $(n=6)$, or primary progressive $(n=2)$ MS. Serum was collected pretreatment $(\mathrm{n}=23)$ or while on therapy including interferon $\beta-1 \mathrm{a}(\mathrm{n}=12)$, interferon $\beta-1 b(n=9)$, glatiramer acetate $(n=5)$, natalizumab $(\mathrm{n}=15)$, fingolimod $(\mathrm{n}=11)$, or alemtuzumab $(\mathrm{n}=1)$.

Controls. Fifty-two adult control patients ( 35 female; median age 55 years, range 24-79) were tested, including patients with other neurologic diseases (epilepsy, Parkinson disease, and peripheral neuropathy; $\mathrm{n}=20$ ) as well as healthy controls $(\mathrm{n}=32$ ).

Visual outcomes. All patients received a visual functional system score (VFSS) based on their visual acuity (rated from 0 to 6) during their acute presentation and at latest follow-up (median follow-up 24 months, mean 20 months, range 2-48 months). This score was based on the VFSS from the EDSS ${ }^{26}$ (table e-3).

Visual field sensitivity was assessed using the central 30-2 program on a Humphrey Visual Field Analyzer (Carl Zeiss Meditec, Dublin, California) at acute presentation and at latest follow-up. The mean deviation (MD) was obtained as a measure of overall visual field sensitivity. A negative MD corresponds to a loss in sensitivity, with normal values ranging from 0 to $-3 \mathrm{~dB} .{ }^{27}$ As the visual field deficit increases, the MD value becomes progressively negative. We graded the sensitivity loss in each eye as mild (MD greater than $-3.0 \mathrm{~dB}$ but less than $-6.0 \mathrm{~dB}$ ), moderate (MD greater than $-6.0 \mathrm{~dB}$ but less than $-20.0 \mathrm{~dB}$ ), or severe (MD greater than $-20.0 \mathrm{~dB}$ ), as described in the Optic Neuritis Treatment Trial. ${ }^{27}$ We assigned scores of 0 (normal), 1 (mild), 2 (moderate), and 3 (severe) to sensitivity loss as determined by MD grades at acute presentation and follow-up (median follow-up 4 months, mean 5.4 months, range 1-13 months).

Optical coherence tomography (OCT) images of the peripapillary retinal nerve fiber layer (RNFL) were acquired using a Stratus OCT (Carl Zeiss Meditec, software version 6.00.599) using the Optic Disc Cube protocol. OCT performed at acute presentation and at latest follow-up (median follow-up 4 months, mean 4.2 months, range 1.5-7 months) was evaluated for the average RNFL thickness for each eye and was compared to age-appropriate normative data provided by the manufacturer. Values above this range reflect swelling, while values below this range reflect thinning of the 
RNFL. ${ }^{28}$ OCT images were rejected if an individual eye had a signal strength less than 8 or if there was a difference of greater than 2 between the 2 eyes. All patients were imaged adequately using fixation with the fellow eye if needed. The fundus was wellimaged from edge to edge within the imaging field. All OCT studies available adhered to these parameters.

Standard protocol approval, registrations, and patient consents. Ethics approval for this study was granted by the Sydney Children's Hospitals Network Human Ethics Committee (12/SCHN/395, SSA/13/WMEAD/53, SSA/13/CRGH/257, SSA/13/RPAH/599), and informed consent was obtained from all patients.

Cloning and expression of human MOG. Full-length human MOG cDNA was cloned from a human fetal brain RNA library (gift from Dr. Monkol Lek). Sequence-verified MOG cDNA was subcloned into pIRES2-ZsGreen1 lentivirus vector, enabling both MOG and ZsGreen to be co-expressed in cells (gift of Dr. Stuart Turville). We used published protocols to transduce and obtain MOG-expressing human embryonic kidney 293 cells (HEK293 $3^{\mathrm{MOG}+}$ ). ${ }^{29}$ Control cells (HEK293 ${ }^{\text {CTL }}$ ) were obtained by transduction of particles with empty pIRES2-ZSGreen vectors.

Cell-based assay for the detection of serum antibodies to cell surface MOG. We used fluorescence-activated cell sorting (FACS) analysis to detect antibody binding of patient serum IgG to surface MOG transduced in HEK293 cells as we have previously described (methodology presented in appendix e-2). ${ }^{30,31}$ Samples were considered positive if they were above threshold on at least 2 of 3 repeated experiments, and the intraassay variation is summarized in appendix e- 2 .

Statistical analysis. The $\chi^{2}$ test with Yates correction was used to compare MOG antibody positivity between patient and control groups, as well as binary clinical features between MOG antibody-positive and -negative groups. No adjustment for multiple testing was performed. The Mann-Whitney test was used to compare continuous variables. Statistics and figures were generated using Prism software version 6.0 (GraphPad Software, La Jolla, CA).

Classification of evidence. This study provides Class II evidence that MOG antibodies are associated with AQP4antibody-negative BON (sensitivity 69\%, 95\% confidence interval [CI] 42\%-87\%; specificity 99\%, 95\% CI 93.7\%-99.8\%). The study is Class II because of the case-control design. Sensitivity was calculated from the proportion of patients with BON positive for MOG antibody (9/13). Specificity was calculated from the proportion of non-BON autoimmune patients (MS and isolated LETM patients) without MOG antibodies (85/86).

RESULTS MOG antibodies and BON in adults. We used FACS to detect antibody binding of patient IgG to surface MOG transduced in HEK293 cells. The mean fluorescence intensity (MFI) was associated with antibody concentration (figure 1A). Using the mean + $3 \times$ SDs of our control population to establish the threshold for positivity, MOG antibodies were detected in 9/23 AQP4 antibody-negative patients with NMO/ NMOSD, compared to $1 / 76$ patients with MS and 0/52 controls (figure 1, B-D; $p<0.0001$ ). None of the MOG antibody-positive patients demonstrated IgM reactivity (figure e-1, appendix e-3). Eight of 11 patients with BON were MOG antibody-positive, compared to $0 / 10$ patients with LETM and $1 / 2$ patients with sequential BON and LETM (figure 1E, table 1). None of the MOG antibody-positive patients had a previous episode of ADEM.

Clinical phenotyping of MOG antibody-positive patients. MOG antibody-positive patients were more often female and younger, often had a preceding infectious prodrome, and were more likely to relapse than MOG antibody-negative patients (table 1, not significant).

The AQP4 antibody-negative NMO/NMOSD cohort as a whole frequently had elevated markers of inflammation or autoimmunity (table e-1), but there were no significant differences between the MOG antibody-positive and -negative patients. The presence of oligoclonal bands in the CSF was uncommon, and patients did not fulfill the revised McDonald criteria ${ }^{25}$ for MS in either group. All MOG antibody-positive patients had brain MRIs that did not fulfill the revised McDonald criteria. Of these, 7 had MRIs performed during acute presentation with optic nerve gadolinium enhancement. One MOG antibody-positive patient had large enhancing cerebral lesions that resolved rapidly with steroids. This patient's imaging did not fulfill the revised McDonald criteria for MS.

Eight of 9 MOG antibody-positive patients had BON (table 2), with the ninth patient demonstrating sequential BON and LETM (figure 1E). Six of 9 had a relapsing course (median episodes 2, range 1-5), although this was not a statistically significant difference compared to the seronegative group. All 9 MOG antibody-positive patients had prominent optic disc swelling, defined as papillitis or optic nerve head swelling visible on fundoscopy at acute presentation. In 6/9 this disc swelling rapidly resolved with steroid therapy. MOG antibody-positive patients were more likely to be rapidly steroid responsive and to relapse on steroid cessation, compared to MOG antibody-negative patients (table $1, p=0.034$ and $p=0.029$, respectively). The treatment of all MOG antibody-positive patients is outlined in table 2. The median follow-up was 28 months (range 6-120).

One of 76 patients with MS was MOG antibodypositive. This patient was a 55-year-old Caucasian woman with clinical and radiologic findings consistent with relapsing-remitting $\mathrm{MS}$ and no previous ADEM or ON episodes. Notably, she had a strongly positive antinuclear antibody titer of 1:2,560.

Persisting MOG antibody seropositivity and relapsing BON. We determined the maximum serum dilution required for a sample to still have a $\Delta \mathrm{MFI}$ above the threshold. Seven MOG antibody-positive patients 
A

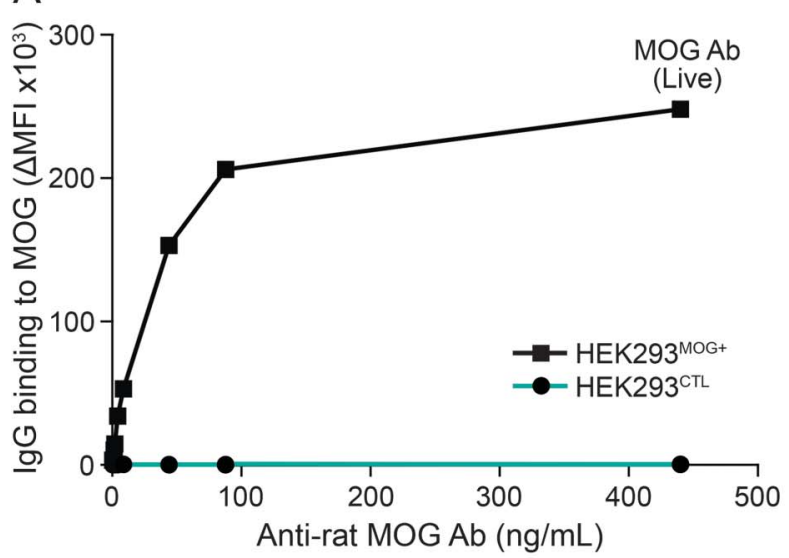

$\mathrm{D}$

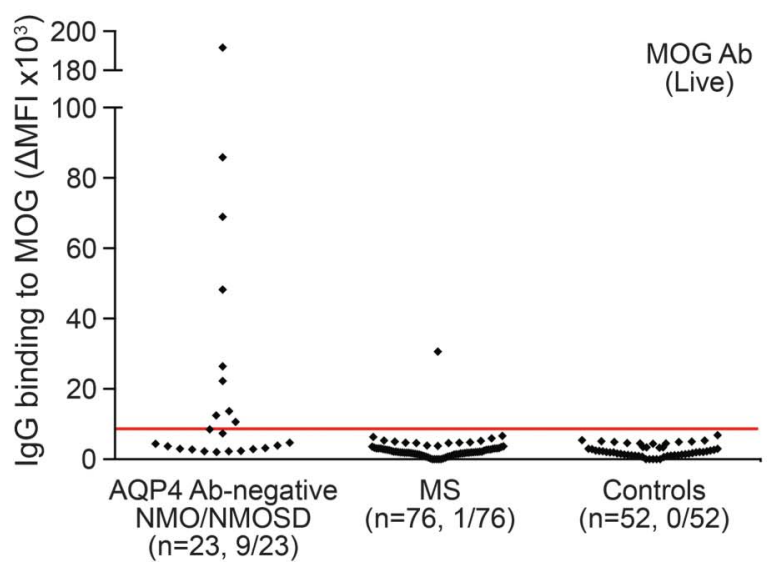

B

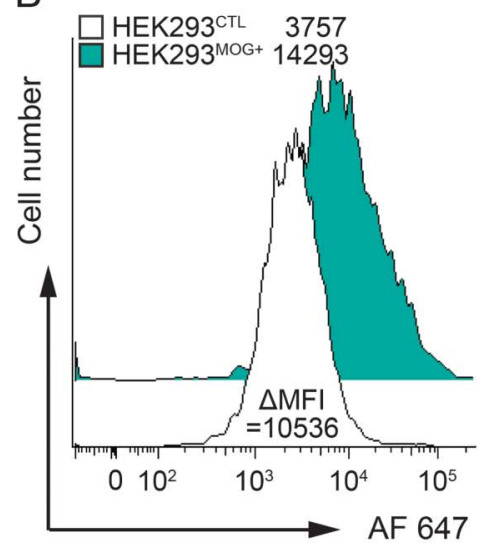

$\mathrm{E}$

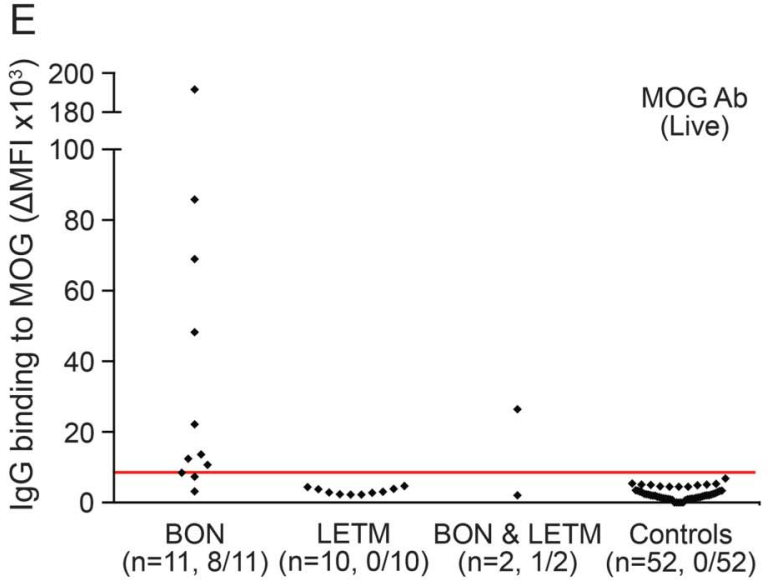

(A) Antibody (Ab) reactivity to myelin oligodendrocyte glycoprotein (MOG) was determined by a flow cytometry live cell-based assay and demonstrated increased immunoglobulin (lg) G binding to MOG with an increasing MOG antibody concentration. $(\mathrm{B}, \mathrm{C})$ Representative examples of flow cytometry histograms for one MOG antibody-positive patient with an intermediate $\triangle \mathrm{MFI}$ (B) and one with a very high $\triangle \mathrm{MFI}$ (C). $\Delta \mathrm{MFI}$ values are noted in the legend. (D) Human surface MOG IgG Abs were detected in 9/23 AQP4 antibody-negative patients with NMO/NMOSD, compared to 1/76 patients with multiple sclerosis (MS) and $0 / 52$ controls. The red line on the graph represents the threshold of positivity. MOG antibody positivity is shown between brackets. A representative experiment out of 3 is shown. (E) $\triangle M F I$ values for all subgroups of AQP4 antibody-negative patients with NMO/NMOSD. AQP4 = aquaporin-4; BON $=$ bilateral and/or recurrent optic neuritis; HEK293 = human embryonic kidney 293 cells; HEK293 ${ }^{\text {TL }}=$ control HEK293 cells; HEK293 ${ }^{\text {MOG }+}=\mathrm{HEK}$ 293 cells expressing MOG; LETM = longitudinally extensive transverse myelitis; MFI = mean fluorescence intensity; NMO/NMOSD = neuromyelitis optica /neuromyelitis optica spectrum disorder.

were tested at serum dilutions ranging from 1:50 to $1: 2,000$. Six of 7 remained positive at $1: 100,5 / 7$ at $1: 200$, and 4/7 at 1:400. Only one patient remained positive at dilutions of 1:1,000 and 1:2,000. MOG antibody-positive patients can have variably high titers (figure 2A).

We obtained serial samples in 4 MOG antibodypositive patients with a relapsing course (median time between samples 22.5 months, range 4-72 months) (figure 2, B-E). Three of them had at least one episode of simultaneous $\mathrm{BON}$, with one having additional unilateral $\mathrm{ON}$ (figure 2, B, C, and E). One patient (figure 2D) had recurrent episodes of unilateral $\mathrm{ON}$ affecting both eyes. $\Delta \mathrm{MFI}$ values showed an overall decline in all patients but remained positive in 3 patients despite treatment and clinical remission.
Patient 4 (figure 2E) had an initial presentation with BON followed within a fortnight by LETM. While his visual recovery was satisfactory, his spinal disease was extensive and debilitating, with a modified Rankin Scale (mRS) score of 5. With aggressive immunosuppression and intensive rehabilitation he made a slow recovery but remained MOG antibody-positive at 8-month followup. He is currently independently mobile with residual sphincter dysfunction and a spastic gait (mRS 2).

MOG antibody-associated BON and visual outcomes. Most MOG antibody-positive patients had significant visual impairment during the acute episode, with 6/9 $(67 \%)$ having a VFSS of 5 or 6 (figure 3A). While 8/9 patients had good visual acuity at follow-up with a VFSS of $0-2$, one patient (patient 7 , table 2) had a significant 
Table 1 Clinical comparison of MOG antibody-positive and -negative patients

\begin{tabular}{|c|c|c|c|}
\hline Clinical and investigation findings & $\begin{array}{l}\text { MOG antibody-positive } \\
(\mathrm{n}=9)\end{array}$ & $\begin{array}{l}\text { MOG antibody-negative } \\
(\mathrm{n}=14)\end{array}$ & p Value ${ }^{a}$ \\
\hline Sex (female) & $6 / 9(67)$ & $6 / 14(43)$ & 0.492 \\
\hline Age at onset, median (range) & $36(22-52)$ & $43(17-59)$ & $0.360^{\mathrm{b}}$ \\
\hline Caucasian ethnicity & $6 / 9(67)$ & $10 / 14(71)$ & 0.809 \\
\hline Infectious prodrome & $6 / 9(67)$ & $4 / 14(29)$ & 0.171 \\
\hline \multicolumn{4}{|l|}{ Clinical presentation } \\
\hline BON & $8 / 9$ (89) & $3 / 14(21.5)$ & 0.006 \\
\hline LETM & $0 / 9(0)$ & 10/14 (71.5) & 0.003 \\
\hline BON and LETM & $1 / 9(11)$ & $1 / 14(7)$ & 0.742 \\
\hline Relapsing disorder & $6 / 9(67)$ & $6 / 14(43)$ & 0.492 \\
\hline No. of episodes, median (range) & $2(1-5)$ & $1(1-8)$ & $0.284^{\mathrm{b}}$ \\
\hline Personal or family history of autoimmunity & 2/9 (22) & $2 / 14(14)$ & 0.624 \\
\hline CSF lymphocytosis & 2/9 (22) & $7 / 14(50)$ & 0.371 \\
\hline Presence of intrathecal CSF oligoclonal bands & $1 / 9$ (11) & $1 / 14(7)$ & 0.742 \\
\hline MRI fulfilling revised McDonald criteria ${ }^{25}$ & $0 / 9(0)$ & $0 / 14(0)$ & NA \\
\hline Rapid steroid response $^{c}$ & $6 / 9(67)$ & $2 / 14(14)$ & 0.034 \\
\hline Relapse with steroid cessation ${ }^{d}$ & $4 / 9(44)$ & $0 / 14(0)$ & 0.029 \\
\hline
\end{tabular}

Abbreviations: $\mathrm{BON}$ = bilateral and/or recurrent optic neuritis; LETM = longitudinally extensive transverse myelitis; $\mathrm{MOG}=$ myelin oligodendrocyte glycoprotein; NA = not applicable.

Data are $\mathrm{n} /$ total tested (\%), unless otherwise specified.

${ }^{a} p$ Values determined using $\chi^{2}$ test with Yates correction, unless otherwise specified.

${ }^{\mathrm{b}} p$ Values calculated using Mann-Whitney test.

${ }^{\mathrm{c}}$ Rapid steroid response defined as a greater than $50 \%$ improvement in visual acuity or Expanded Disability Status Scale score within 24 hours of commencing IV steroids.

${ }^{\mathrm{d}}$ Relapse with steroid cessation was defined as acute worsening within 48 hours of cessation of IV steroids.

residual deficit with a VFSS of 5 (figure $3 \mathrm{~A}$ ) (median follow-up interval 24 months, mean 20 months, range 2-48 months).

Visual fields were assessed in 5 MOG antibodypositive patients (10 eyes) at acute presentation and follow-up (median follow-up 4 months, range 1-13 months) (figure 3, B and C). Seven of 10 eyes had a moderate or severe visual field deficit at acute presentation. Follow-up demonstrated an improvement in all eyes, with the MD approaching the normal range (figure $3 \mathrm{~B}$ ) and visual field deficits scoring as normal or mildly affected in 8/10 eyes (figure 3C).

We reviewed RNFL thickness as measured by OCT during an acute episode of $\mathrm{ON}$ and at follow-up. While acute $\mathrm{ON}$ can result in increased peripapillary RNFL thickness (figure 3, D-F), RNFL thickness returns toward the normal range with clinical resolution (figure 3D). Three patients demonstrated evidence of RNFL thinning (figure 3, E and G), suggesting axonal loss and irreversible damage. Patient 7 (table 2, appendix e-4) experienced 5 relapses in a 4-year period. Delayed diagnosis and initiation of immunotherapy were possible contributors to a poor follow-up VFSS and significant RNFL thinning in this patient.

Visual outcomes in the MOG antibody-negative patients with $\mathrm{BON}$ are outlined in appendix e-5.
Together these findings suggest that visual acuity, visual field deficits, and RNFL thickness improve in the majority of patients with MOG antibody-associated BON; however, some patients exhibit sustained visual impairment.

DISCUSSION Using a flow cytometry cell-based assay, we found that antibodies targeting human native surface full-length MOG may be a clinical biomarker in adults with AQP4 antibody-negative BON. We provide clinical characterization of this condition as a relapsing disorder, frequently associated with prominent disc swelling, that is steroid sensitive and often steroid dependent. While early recognition and institution of therapy can result in a favorable outcome, MOG antibody-associated BON has the potential to result in long-term visual impairment.

In recent years, microscopy or flow cytometry cell-based assays have been crucial in establishing MOG as an unequivocal antibody target in human demyelination. ${ }^{11}$ In particular, flow cytometry has emerged as a sensitive detection method, ${ }^{6,14,16,21,32}$ with recent confirmation of the surface expression of the dominant MOG epitopes. ${ }^{33}$

We describe that surface MOG IgG antibodies have a strong association with $\mathrm{BON}$ in adults. 


\begin{tabular}{|c|c|c|c|c|c|c|c|c|c|c|}
\hline \multirow[t]{2}{*}{ Table 2} & \multicolumn{10}{|c|}{ Clinical characterization of MOG antibody-positive patients } \\
\hline & $\begin{array}{l}\text { Age at first } \\
\text { episodel } \\
\text { sex }\end{array}$ & $\begin{array}{l}\text { Clinical } \\
\text { events }\end{array}$ & $\begin{array}{l}\text { Visual functional } \\
\text { system score at } \\
\text { onset }\end{array}$ & $\begin{array}{l}\text { Spinal symptoms in } \\
\text { absence of spinal lesion } \\
\text { on imaging }\end{array}$ & $\begin{array}{l}\text { No. of optic neuritis } \\
\text { episodes: total } \\
\text { (unilateral/bilateral) }\end{array}$ & Treatment regimen & $\begin{array}{l}\text { Rapid } \\
\text { steroid } \\
\text { response }\end{array}$ & $\begin{array}{l}\text { Relapse on } \\
\text { steroid } \\
\text { cessation }\end{array}$ & $\begin{array}{l}\text { Disease } \\
\text { duration and } \\
\text { follow-up, } \mathrm{mo}^{\mathrm{a}}\end{array}$ & $\begin{array}{l}\text { Visual functional } \\
\text { system score at } \\
\text { latest follow-up }\end{array}$ \\
\hline Patient 1 & $26 / F$ & BON & 2 & Lhermitte phenomenon & $2(1 / 1)$ & $\begin{array}{l}\text { IV MP } \times 2 \text { courses, oral } \\
\text { prednisone }\end{array}$ & Yes & Yes & 52 & 0 \\
\hline Patient 2 & $32 / \mathrm{M}$ & BON & 5 & No & $2(0 / 2)$ & $\begin{array}{l}\text { IV MP } \times 2 \text { courses, oral } \\
\text { prednisone }\end{array}$ & Yes & Yes & 7 & 0 \\
\hline Patient 3 & $52 / F$ & BON & 2 & $\begin{array}{l}\text { Lhermitte phenomenon, } \\
\text { limb paresthesia }\end{array}$ & $\begin{array}{l}4(4 / 0) ; 2 \text { left ON and } 2 \\
\text { right ON }\end{array}$ & IV MP $\times 2$ courses & Yes & No & 120 & 2 \\
\hline Patient 4 & 29/M & $\begin{array}{l}\text { BON and } \\
\text { LETM }\end{array}$ & 2 & NA as patient had LETM & $1(0 / 1) ; 1$ LETM & $\begin{array}{l}\text { IV MP } \times 2 \text { courses, } \\
\mathrm{PE} \text {, maintenance MMF and oral } \\
\text { prednisone }\end{array}$ & No & No & 9 & 1 \\
\hline Patient 5 & $45 / F$ & BON & 6 & No & $3(2 / 1)$ & $\begin{array}{l}\text { IV MP } \times 3 \text { courses, glatiramer } \\
\text { acetate }\end{array}$ & Yes & Yes & 28 & 2 \\
\hline Patient 6 & $36 / F$ & BON & 6 & No & $1(0 / 1)$ & IV MP & Yes & No & 6 & 2 \\
\hline Patient $7^{b}$ & 22/M & BON & 6 & $\begin{array}{l}\text { Bladder symptoms and } \\
\text { lower limb paresthesia }\end{array}$ & $\begin{array}{l}5(5 / 0) ; 3 \text { right } \mathrm{ON} \text { and } 2 \\
\text { left ON }\end{array}$ & $\begin{array}{l}\text { IFN, latest episode IV MP, } \\
\text { maintenance MMF and oral } \\
\text { prednisone, rituximab }\end{array}$ & No & No & 58 & 5 \\
\hline Patient 8 & $51 / F$ & BON & 5 & $\begin{array}{l}\text { Sphincter dysfunction } \\
\text { and lower limb } \\
\text { paresthesia }\end{array}$ & $1(0 / 1)$ & No treatment & NA & NA & 24 & 2 \\
\hline Patient $9^{c}$ & $38 / \mathrm{F}$ & BON & 5 & Lower limb paresthesia & $1(0 / 1)$ & $\begin{array}{l}\text { IV MP } \times 2, \mathrm{PE} \text {, maintenance MMF } \\
\text { and oral prednisone }\end{array}$ & Yes & Yes & 29 & 2 \\
\hline $\begin{array}{l}\text { Group } \\
\text { summary }\end{array}$ & $\begin{array}{l}\text { Median } \\
\text { (range); } 36 \\
(22-52)\end{array}$ & $\begin{array}{l}\text { BON } 8 / 9 \\
\text { BON and } \\
\text { LETM } 1 / 9\end{array}$ & $\begin{array}{l}\text { Median (range); } 5 \\
(2-6)\end{array}$ & $5 / 8$ with isolated $\mathrm{BON}$ & $\begin{array}{l}\text { Median total episodes } \\
\text { (range); } 2 \text { (1-5) }\end{array}$ & $\begin{array}{l}\text { IV MP } 8 / 9 \text {; oral prednisone } 5 / 9 ; \\
\text { PE } 2 / 9 \text {; MMF } 3 / 9 \text {; rituximab } 1 / 9\end{array}$ & $6 / 9$ & $4 / 9$ & $\begin{array}{l}\text { Median (range); } \\
28(6-120)\end{array}$ & Median (range); 2 (0-5) \\
\hline
\end{tabular}

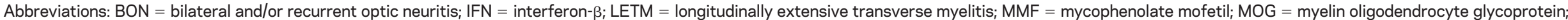
IV MP = intravenous methylprednisolone; $\mathrm{NA}=$ not applicable; $\mathrm{ON}=$ optic neuritis; $\mathrm{PE}$ = plasma exchange

${ }^{a}$ All patients had clinical follow-up from the time of disease onset.

${ }^{b}$ Personal history of Henoch-Schonlein purpura.

${ }^{\mathrm{c}}$ Two first-degree relatives with type 1 diabetes, one first-degree relative with lymphocytic colitis. 

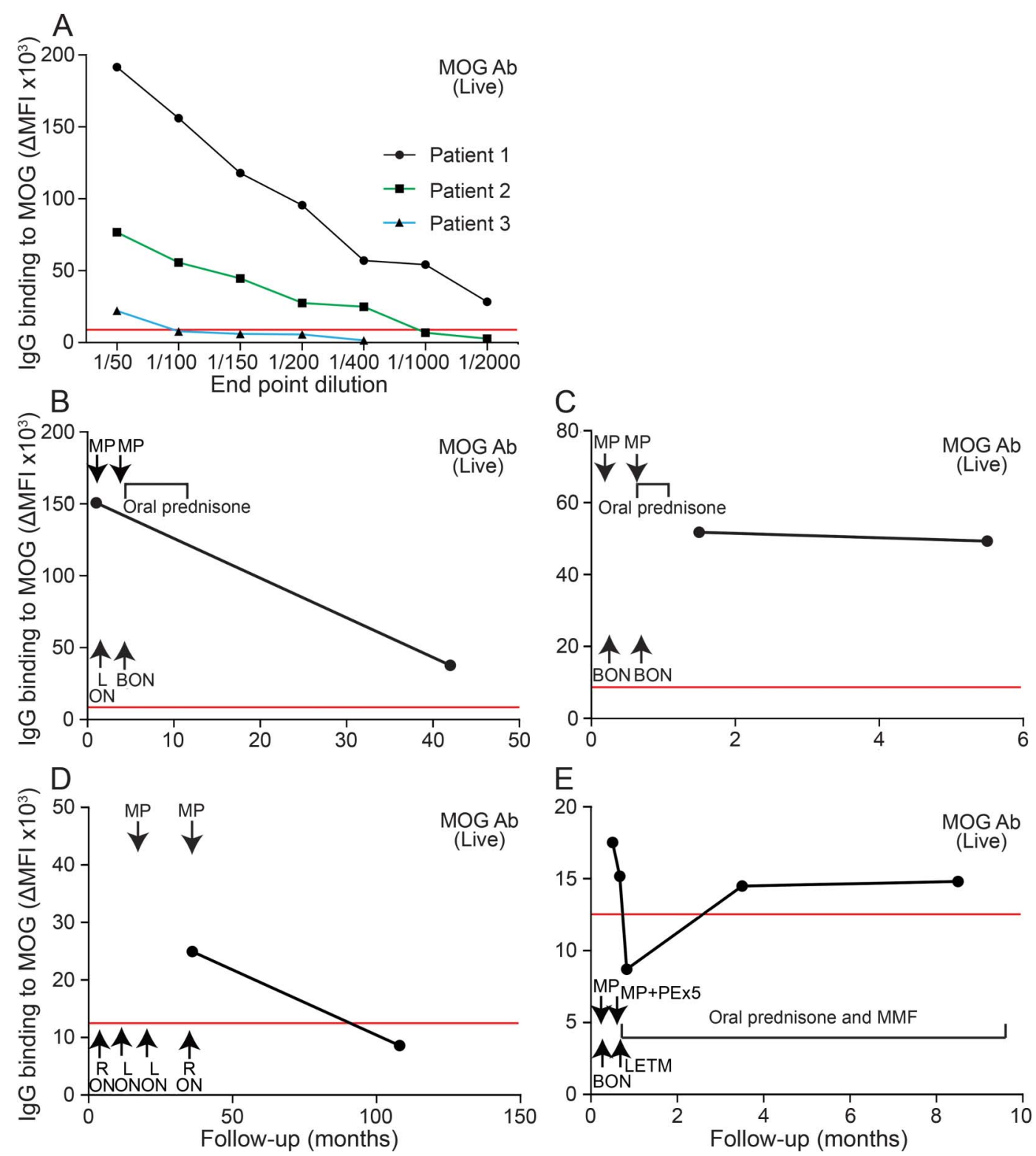

(A) Serial dilutions of MOG antibody-positive samples show differing immunoglobulin (lg) G binding. The end point dilution where a sample remained above the positive threshold (red line) ranged from 1:50 to 1:2,000. For clarity, only 3 representative patients are shown. (B-E) Serial samples in 4 MOG antibody-positive patients are shown. A representative dot plot out of 3 experiments is shown. Red lines on the graphs represent the threshold of positivity. Black circles represent times of serum collection, arrows pointing up represent a clinical attack, arrows pointing down represent commencement of treatment. (B) Patient 1 experienced a unilateral episode of left optic neuritis (ON) (normal MRI brain) that responded rapidly to pulsed steroids; however, cessation of steroids prompted a bilateral simultaneous $\mathrm{ON}$ relapse requiring further treatment. There were no further relapses and a good visual outcome. The initial sample was collected during the first presentation. A serial sample collected during remission 4 years later remains positive, albeit with a reduced $\Delta \mathrm{MFI}$. (C) Patient 2 similarly experienced 2 episodes of BON (normal MRI brain). The first sample was collected within 1 month of his relapse; a serial sample 4 months later during remission remained seropositive. (D) Patient 3 experienced 4 episodes of recurrent unilateral ON (MRI brain normal) affecting both eyes and was treated on 2 occasions with pulsed steroids. While the first serum sample within 1 month of her fourth relapse showed elevated MOG antibodies, 6-year follow-up revealed no further ON episodes and a $\triangle M F I$ below the positive threshold at remission. (E) Patient 4 presented with sequential BON and longitudinally extensive transverse myelitis (LETM) (MRI brain normal) and received aggressive immunotherapy. While his visual acuity has improved, he continues to experience moderate visual field deficits and has residual motor and sphincter disability related to spinal involvement. Serial samples were collected at initial presentation, during his relapse, and during remission. He remains seropositive more than 8 months after presentation. $\mathrm{Ab}=$ antibody; $\mathrm{BON}=$ bilateral and/or recurrent optic neuritis; MFI = mean fluorescence intensity; MMF = mycophenolate mofetil; MOG = myelin oligodendrocyte glycoprotein; $\mathrm{MP}=$ Intravenous methylprednisolone; $\mathrm{PE}=$ plasma exchange. 

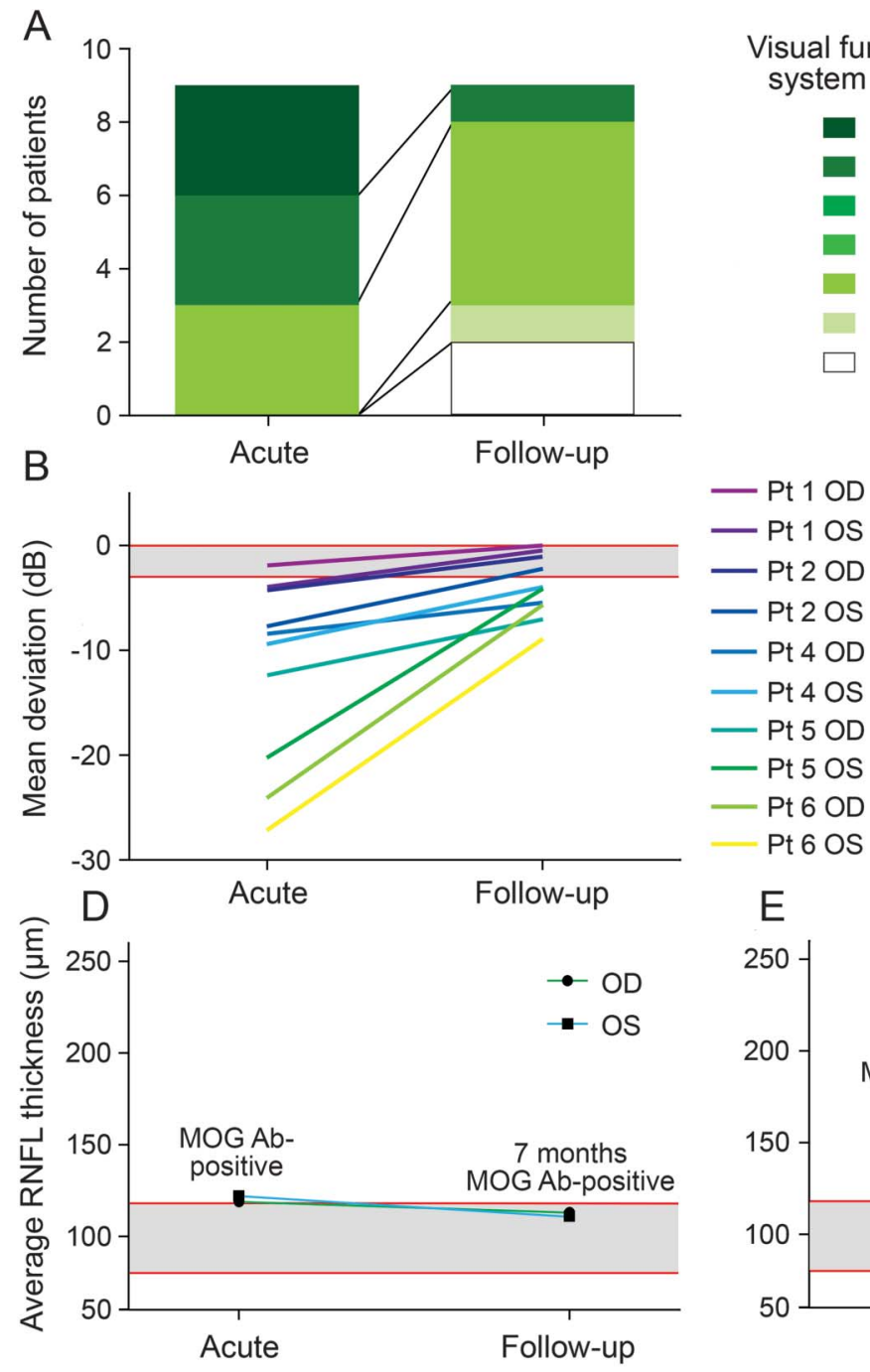

$\mathrm{E}$

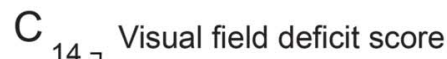

Cisual field deficit score

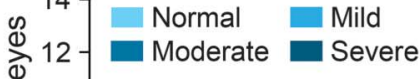

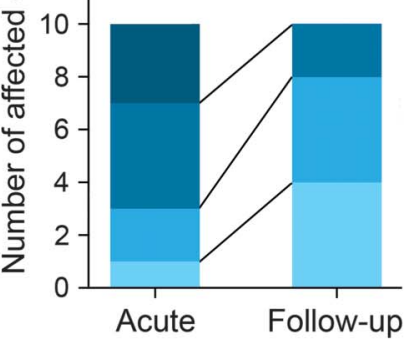

E

Visual functional system score
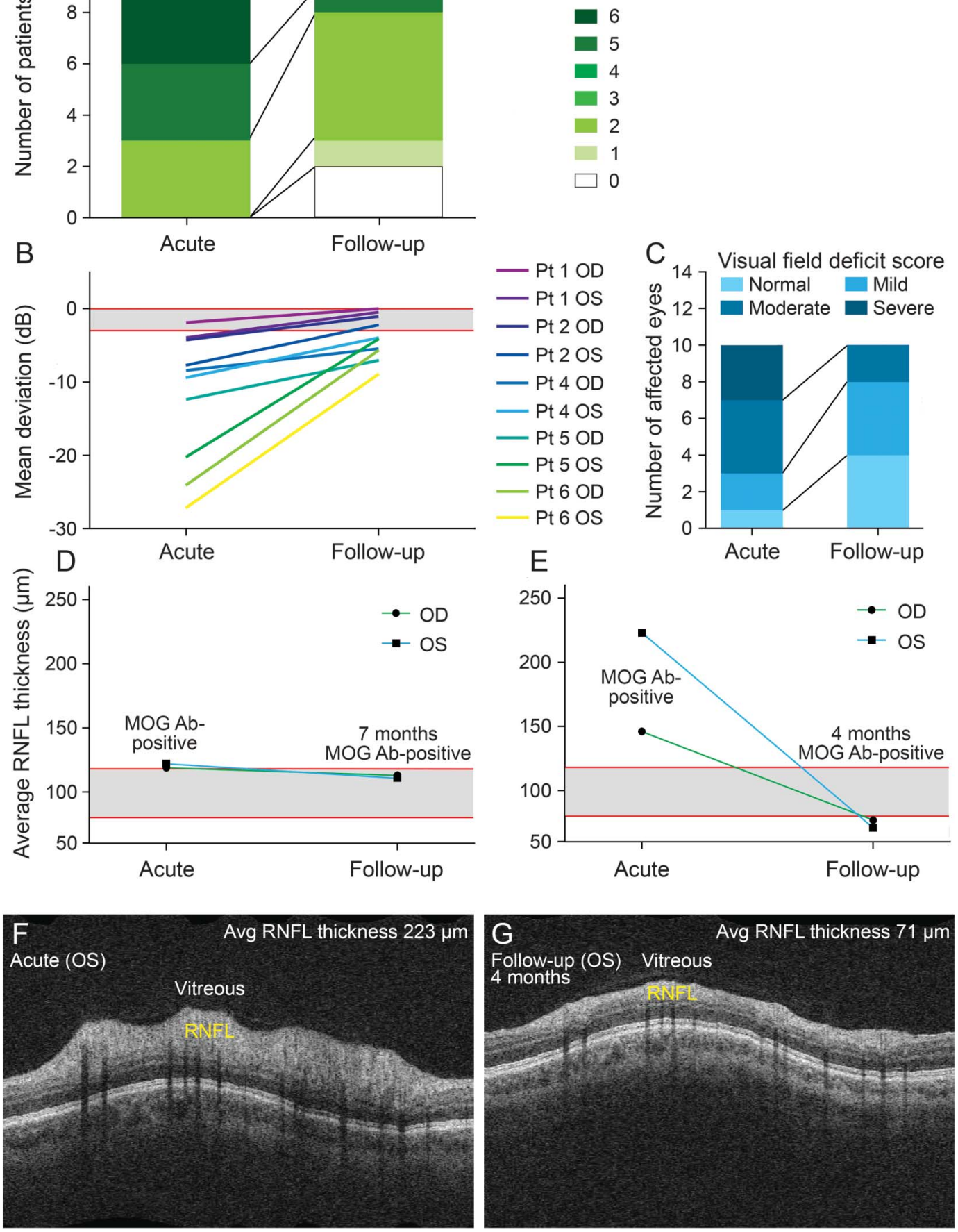

(A) Visual functional system scores for MOG antibody-positive patients taken at the time of acute presentation and at latest follow-up demonstrate that the majority of patients experienced an improvement in visual acuity at follow-up. (B) Visual field deficits in 5 patients in both left (OS) and right (OD) eyes as measured by the mean deviation also demonstrate improvement at latest follow-up and approach the normal range (gray region between red lines, 0 to $-3 \mathrm{~dB}$ ). (C) The majority of affected eyes had a moderate to severe visual field deficit at onset but experienced an improvement in these scores. However, 2 affected eyes had a moderate residual deficit at latest follow-up. (D-G) Optical coherence tomography allowed for estimation of average peripapillary retinal nerve fiber layer (RNFL) thickness. During an acute episode of optic neuritis, swelling results in increased RNFL thickness (F). With resolution of the attack, RNFL thickness can either return toward the normal range (shaded region) (D) or result in RNFL thinning ( $E$ and $G$ ). Ab = antibody; $B O N=$ bilateral optic neuritis; $M O G=$ myelin oligodendrocyte glycoprotein. 
The fact that $39 \%$ of AQP4 antibody-negative patients with $\mathrm{NMO} / \mathrm{NMOSD}$ in our cohort were positive for MOG antibodies renders this a potentially useful biomarker. We detected an IgG rather than an IgM antibody response, implying this is not an acute immunologic response to injury but rather a more mature response. Seven of 9 MOG antibodypositive patients had one or more episodes of simultaneous BON, with 2 having additional episodes of unilateral ON. Two of 9 MOG antibody-positive patients had recurrent episodes of unilateral $\mathrm{ON}$ affecting both eyes. Our group described MOG antibodies in pediatric patients with BON, further strengthening this clinical association. ${ }^{34} \mathrm{~A}$ similar association with MOG antibody positivity and bilateral simultaneous $\mathrm{ON}$ was recently reported. ${ }^{24} \mathrm{MOG}$ antibodies should be a diagnostic consideration in any patient with recurrent $\mathrm{ON}$, whether they present unilaterally or bilaterally. We additionally found that prominent optic disc swelling was noted in all 9 MOG antibody-positive patients acutely; this appearance is not typical of ON related to MS and should prompt testing for MOG antibodies. ${ }^{35}$ Of interest, chronic relapsing inflammatory optic neuropathy (CRION) describes a group of patients with recurrent optic neuropathy who are largely AQP4 antibody-negative. ${ }^{36,37}$ The diagnostic criteria for CRION include relapsing disease, loss of visual function, NMO-IgG seronegativity, optic nerve contrast enhancement, response to immunosuppressive therapy, and relapse on withdrawal of therapy. ${ }^{37}$ This description is largely similar to the clinical characteristics of our MOG antibody-positive cohort, and it is possible that a subset of patients labeled as CRION may indeed have MOG antibody-associated BON.

One MOG antibody-positive patient had LETM in the context of a preceding attack of $\mathrm{BON}$. This fulminant presentation of sequential $\mathrm{BON}$ and LETM is uncommon in AQP4 antibody-positive $\mathrm{NMO}$ and reminiscent of the original descriptions of Devic disease. ${ }^{22}$ A recent study ${ }^{23}$ described 9 patients with MOG antibodies, the majority of whom had transverse myelitis. All our MOG antibody-positive patients had both brain and spine MRIs performed. In our cohort, none of the patients with radiologically defined LETM had MOG antibodies. Notably, 5 of our patients with MOG antibody-associated BON did have symptoms suggestive of spinal involvement, including Lhermitte phenomenon, limb paresthesia, and sphincter dysfunction, despite a normal MRI spine. This suggests that cord involvement may occur without clinical or radiologic evidence of myelitis. The use of full-length human MOG in our cellbased assay as opposed to C-terminal truncated human MOG used by other groups $s^{23,38}$ may account for some differences in findings. In addition, 14/23 AQP4 antibody-negative patients with NMO/NMOSD in our cohort were also MOG antibody-negative, suggesting there may be other antigen targets.

Our cohort of MOG antibody-positive patients was predominantly Caucasian. This is in keeping with recent findings and contrasts with AQP4 antibody-positive patients, who are more likely to be non-Caucasian. ${ }^{78}$ A recent report of $16 \mathrm{MOG}$ antibody-positive patients of a similar median age found that most patients were male. ${ }^{24}$ We did not find a statistically significant association with sex, age at onset, and MOG antibody status. In our cohort, the 9 MOG antibody-positive patients did not have intrathecal oligoclonal bands or radiology consistent with MS, suggesting that this condition may be an immunologic entity that is distinct from both AQP4 antibody-positive NMO and MS. While we did not test a cohort of AQP4 antibodypositive patients for MOG antibodies in the context of this study, AQP4- and MOG-antibody double positivity has been seldom reported ${ }^{23,24,39,40}$; therefore, the evaluation of the prevalence and clinical significance of double seropositive patients is a point of interest for future work.

The majority of MOG antibody-positive patients in our cohort had a propensity to relapse and remained persistently seropositive. This is a novel finding in adults, as 2 recently published cohorts have suggested that MOG antibody positivity is associated with a monophasic illness. ${ }^{23,24}$ The presence of relapses has been observed in pediatric patients with MOG antibodies and LETM or recurrent or bilateral ON. ${ }^{15,21}$ Notably, a number of our MOG antibody-positive patients had previous treatment with short courses of pulsed steroids alone and had a propensity to relapse. This may indicate that early and sustained immunotherapy with multiple agents, including steroidsparing maintenance immunosuppression, may be more effective in maintaining disease remission. Further studies addressing the clinical implications of persistent seropositivity on relapse risk and therapeutic approaches in patients with MOG antibodyassociated $\mathrm{BON}$ are required.

Conventional measures of disability such as the $\mathrm{EDSS}^{26}$ or mRS may not be appropriate in patients with $\mathrm{BON}$, as visual impairment alone does not rate highly on such scales despite causing major functional disability. Previous studies highlight the favorable clinical outcomes of patients with MOG antibody-positive NMO/NMOSD. ${ }^{22,23}$ The majority of our MOG antibody-positive patients did indeed demonstrate an improvement of visual acuity and visual field deficits with early immunotherapy, suggesting that this condition may be treatable; however, this improvement was not universal. A minority of our seropositive patients did have 
significant residual deficits in terms of visual acuity, visual field loss, and RNFL thinning. Although most patients had preserved visual acuity, some had evidence of concomitant RNFL thinning, which may represent a vulnerability to sustained visual impairment in the context of relapses. In addition to visual dysfunction, spinal cord-related disability may also persist, as in our patient with sequential BON and LETM. These results highlight the fact that MOG antibody-associated demyelination may not always have a favorable outcome.

Due to the retrospective study design, most samples were obtained pretreatment; however, some patients had received steroids or other immunosuppressive therapy at the time of sample collection. Despite this, the strong association of MOG antibody positivity with the clinical phenotype of relapsing $\mathrm{BON}$ with prominent optic disc swelling is novel and an important contribution to the field. Evaluation of visual fields was retrospective, and half of the antibody-positive patients had both acute and convalescent OCT results. Nonetheless, our study is the first attempt to objectively define visual acuity, visual field deficits, and RNFL in MOG antibody-positive patients and provides important insights on disease pathogenesis.

Taken together, our findings suggest that MOG antibody-associated BON may be a distinct immunologic entity with a characteristic clinical and therapeutic profile. Detection of MOG antibodies may assist with the early differentiation of this condition from AQP4 antibody-positive NMO and MS, and MOG antibodies may prove to be an essential biomarker with diagnostic and therapeutic implications.

\section{AUTHOR AFFILIATIONS}

From the Neuroimmunology Group (S.R., V.M., R.-Y.A.K., K.P., N.S., R.C.D., F.B.), Institute for Neuroscience and Muscle Research, The Kids Research Institute at the Children's Hospital at Westmead, Sydney Medical School, University of Sydney; Departments of Neurology (S.R., A.H., A.F.B., V.S.F.) and Ophthalmology (A.H.), Westmead Hospital, Sydney; Department of Neurology (S.W.R., C.Y.), Concord Repatriation General Hospital, Sydney; Brain and Mind Research Institute (S.W.R., M.B.), University of Sydney; Department of Neurology (J.D.P., C.Y.), Royal North Shore Hospital, Central Clinical School, University of Sydney; Department of Neurology (M.B., M.G.), Royal Prince Alfred Hospital, Sydney; Institute for Immunology and Allergy Research (P.N.G., G.S., D.B.), Westmead Millennium Institute for Medical Research, University of Sydney; and Western Clinical School (S.V.), University of Sydney, Neuroscience Research Australia, Sydney, Australia.

\section{AUTHOR CONTRIBUTIONS}

Study conception: S.R., R.C.D., F.B. Study design: all authors. Sample acquisition: S.R., S.W.R., A.H., J.D.E.P., M.B., P.N.G., C.Y., D.B., V.S.C.F., A.F.B. Acquisition of laboratory data: S.R., V.M., R.-Y.A.K., F.B. Acquisition of clinical data: S.R., S.W.R., A.H., J.D.E.P., M.B., P.N.G., M.G. Study supervision, analysis and interpretation: S.R., R.C.D., F.B. Writing of first draft: S.R., R.C.D., F.B. Editing and revising final draft: all authors.

\section{ACKNOWLEDGMENT}

The authors thank all the patients and family members who participated in this study. The authors thank Dr. Todd Hardy for providing clinical information on one patient, Dr. Maggie Wang for use of the Flow Cytometry Core Facility of the Westmead Millennium Institute (Australia), Professor David Fulcher and Dr. Roger Silvestrini from the Institute for Clinical Pathology and Medical Research (ICPMR, Westmead Australia) for the AQP4 antibody testing, and Dr. Elizabeth Barnes for her assistance with statistical analyses.

\section{STUDY FUNDING}

This study was funded by Multiple Sclerosis Research Australia, the Trish MS Research Foundation, the Star Scientific Foundation (Australia), MS Angels Melbourne (Australia), the Petre Foundation (Australia), and the National Health and Medical Research Council (Australia).

\section{DISCLOSURE}

S. Ramanathan has received a scholarship from the National Health and Medical Research Council (Australia). S.W. Reddel is on the scientific advisory board for CSL, Baxter, Genzyme, Biogen, and National Immunoglobulin Governmental Advisory Council, Australia; has received funding from CSL, Genzyme, and Biogen, is employed by NSW Health, Australia; has received research support from Genzyme and Beeren Foundation; and holds stock with Sydney Neurology and Medical Safety Systems. A. Henderson reports no disclosures. J.D.E. Parratt is on the scientific advisory board for Genzyme and Novartis; has received travel funding or honoraria from Biogen, Genzyme/Sanofi, and Merck Serono; and has received research support from Multiple Sclerosis Research Australia. M. Barnett is on the scientific advisory board for Novartis and Genzyme-Sanofi and has received research support from Novartis, Genzyme-Sanofi, Bio-CSL, NSW Government (Australia), and Nerve Research Foundation. P.N. Gatt, V. Merheb, and R-Y.A. Kumaran report no disclosures. K. Pathmanadavel has received research support from Petre Foundation. N. Sinmaz has received research support from Australian Postgraduate Award. M. Ghardiri has received travel funding from Genzyme, BioCSL, Biogen Idec, and Novartis and funding from Novartis. C. Yiannikas is on the advisory board for Biogen IdecBG12; has received travel funding from Novartis and Biogen; and is a consultant for Allergan. S. Vucic is on the advisory board for Merck Serono Australia, Novartis, and Bayer Schering and is a consultant for Merck Serono Australia. G. Stewart is on the advisory board for SAB Actellion, Basel and received research support from Pfizer International and National Health \& Medical Research Council of Australia. A.F. Bleasel reports no disclosures. D. Booth has received honoraria from Genzyme, Biogen Idec, Merck Serono, Sanofi Aventis, and Pfizer; is an editor for PLoS ONE; holds a patent for prediction of response to therapy for hepatitis C; and has received research support from Pfizer, National Health Medical Research Council Australia, Multiple Sclerosis Research Australia, The Australian Research Council, and the Leukemia Foundation. V.S.C. Fung is on the advisory board for Abbott, Allergan, Boehringer-Ingelheim, Hospira, Ipsen, Lundbeck, Novartis, Solvay, and UCB; has received funding from Boehringer-Ingelheim and Ipsen; is on the editorial board for Movement Disorders Clinical Practice, Journal of Clinical Movement Disorders, Basal Ganglia, and F1000 Research; and is employed by Western Sydney Local Health Network, NSW, Australia. R.C. Dale is on the advisory board for Queensland Children's Medical Institute; received honoraria from Biogen Idec; is on the editorial board for MSARD, Neurology: Neuroimmunology \& Neuroinflammation, and the European Journal of Paediatric Neurology; has received publishing royalties from Biogen Idec; and has received research support from NHMRC. F. Brilot is an associate editor for Journal of Visualized Experiments and has received research support from The Star Scientific Foundation Australia, The Trish Multiple Sclerosis Foundation Australia, Multiple Sclerosis Research Australia, Multiple Sclerosis Angels Melbourne Australia, NHMRC, and Petre Foundation Australia. Go to Neurology.org/nn for full disclosures.

Received June 1, 2014. Accepted in final form September 11, 2014.

\section{REFERENCES}

1. Lennon VA, Wingerchuk DM, Kryzer TJ, et al. A serum autoantibody marker of neuromyelitis optica: distinction from multiple sclerosis. Lancet 2004;364:2106-2112. 
2. Lennon VA, Kryzer TJ, Pittock SJ, Verkman AS, Hinson SR. IgG marker of optic-spinal multiple sclerosis binds to the aquaporin- 4 water channel. J Exp Med 2005; 202:473-477.

3. Kitley J, Leite MI, Nakashima I, et al. Prognostic factors and disease course in aquaporin- 4 antibody-positive patients with neuromyelitis optica spectrum disorder from the United Kingdom and Japan. Brain 2012;135:1834-1849.

4. Wingerchuk DM, Lennon VA, Pittock SJ, Lucchinetti CF, Weinshenker BG. Revised diagnostic criteria for neuromyelitis optica. Neurology 2006;66:1485-1489.

5. Wingerchuk DM, Lennon VA, Lucchinetti CF, Pittock SJ, Weinshenker BG. The spectrum of neuromyelitis optica. Lancet Neurol 2007;6:805-815.

6. Waters PJ, McKeon A, Leite MI, et al. Serologic diagnosis of NMO: a multicenter comparison of aquaporin-4- $\operatorname{IgG}$ assays. Neurology 2012;78:665-671.

7. Marignier R, Bernard-Valnet R, Giraudon P, et al. Aquaporin4 antibody-negative neuromyelitis optica: distinct assay sensitivity-dependent entity. Neurology 2013;80:2194-2200.

8. Jiao Y, Fryer JP, Lennon VA, et al. Updated estimate of AQP4-IgG serostatus and disability outcome in neuromyelitis optica. Neurology 2013;81:1197-1204.

9. Schluesener HJ, Sobel RA, Linington C, Weiner HL. A monoclonal antibody against a myelin oligodendrocyte glycoprotein induces relapses and demyelination in central nervous system autoimmune disease. J Immunol 1987; 139:4016-4021.

10. Genain CP, Nguyen MH, Letvin NL, et al. Antibody facilitation of multiple sclerosis-like lesions in a nonhuman primate. J Clin Invest 1995;96:2966-2974.

11. Reindl M, Di Pauli F, Rostasy K, Berger T. The spectrum of MOG autoantibody-associated demyelinating diseases. Nat Rev Neurol 2013;9:455-461.

12. Storch MK, Stefferl A, Brehm U, et al. Autoimmunity to myelin oligodendrocyte glycoprotein in rats mimics the spectrum of multiple sclerosis pathology. Brain Pathol 1998;8:681-694.

13. Collongues N, Chanson JB, Blanc F, et al. The Brown Norway opticospinal model of demyelination: does it mimic multiple sclerosis or neuromyelitis optica? Int J Dev Neurosci 2012;30:487-497.

14. Brilot F, Dale RC, Selter RC, et al. Antibodies to native myelin oligodendrocyte glycoprotein in children with inflammatory demyelinating central nervous system disease. Ann Neurol 2009;66:833-842.

15. Rostasy K, Mader S, Schanda K, et al. Anti-myelin oligodendrocyte glycoprotein antibodies in pediatric patients with optic neuritis. Arch Neurol 2012;69:752-756.

16. McLaughlin KA, Chitnis T, Newcombe J, et al. Age-dependent $\mathrm{B}$ cell autoimmunity to a myelin surface antigen in pediatric multiple sclerosis. J Immunol 2009;183:4067-4076.

17. Rostasy K, Mader S, Hennes EM, et al. Persisting myelin oligodendrocyte glycoprotein antibodies in aquaporin-4 antibody negative pediatric neuromyelitis optica. Mult Scler 2013;19:1052-1059.

18. Mader S, Gredler V, Schanda K, et al. Complement activating antibodies to myelin oligodendrocyte glycoprotein in neuromyelitis optica and related disorders. J Neuroinflammation 2011;8:184.

19. Lalive PH, Menge T, Delarasse C, et al. Antibodies to native myelin oligodendrocyte glycoprotein are serologic markers of early inflammation in multiple sclerosis. Proc Natl Acad Sci U S A 2006;103:2280-2285.
20. Zhou D, Srivastava R, Nessler S, et al. Identification of a pathogenic antibody response to native myelin oligodendrocyte glycoprotein in multiple sclerosis. Proc Natl Acad Sci U S A 2006;103:19057-19062.

21. Probstel AK, Dornmair K, Bittner R, et al. Antibodies to MOG are transient in childhood acute disseminated encephalomyelitis. Neurology 2011;77:580-588.

22. Kitley J, Woodhall M, Waters P, et al. Myelin-oligodendrocyte glycoprotein antibodies in adults with a neuromyelitis optica phenotype. Neurology 2012;79:1273-1277.

23. Kitley J, Waters P, Woodhall M, et al. Neuromyelitis optica spectrum disorders with aquaporin- 4 and myelinoligodendrocyte glycoprotein antibodies: a comparative study. JAMA Neurol 2014;71:276-283.

24. Sato DK, Callegaro D, Lana-Peixoto MA, et al. Distinction between MOG antibody-positive and AQP4 antibody-positive NMO spectrum disorders. Neurology 2014;82:474-481.

25. Polman $\mathrm{CH}$, Reingold SC, Banwell B, et al. Diagnostic criteria for multiple sclerosis: 2010 Revisions to the McDonald criteria. Ann Neurol 2011;69:292-302.

26. Kurtzke JF. Rating neurologic impairment in multiple sclerosis: an expanded disability status scale (EDSS). Neurology 1983;33:1444-1452.

27. Keltner JL, Johnson CA, Spurr JO, Beck RW. Baseline visual field profile of optic neuritis. The experience of the optic neuritis treatment trial. Optic Neuritis Study Group. Arch Ophthalmol 1993;111:231-234.

28. Kupersmith MJ, Mandel G, Anderson S, Meltzer DE, Kardon R. Baseline, one and three month changes in the peripapillary retinal nerve fiber layer in acute optic neuritis: relation to baseline vision and MRI. J Neurol Sci 2011; 308:117-123.

29. Aggarwal A, Iemma TL, Shih I, et al. Mobilization of HIV spread by diaphanous 2 dependent filopodia in infected dendritic cells. PLoS Pathog 2012;8:e1002762.

30. Amatoury M, Merheb V, Langer J, Wang XM, Dale RC, Brilot F. High-throughput flow cytometry cell-based assay to detect antibodies to n-Methyl-D-aspartate receptor or Dopamine-2 receptor in human serum. J Vis Exp 2013; 81:e50935.

31. Dale RC, Merheb V, Pillai S, et al. Antibodies to surface dopamine-2 receptor in autoimmune movement and psychiatric disorders. Brain 2012;135:3453-3468.

32. O'Connor KC, McLaughlin KA, De Jager PL, et al. Selfantigen tetramers discriminate between myelin autoantibodies to native or denatured protein. Nat Med 2007;13: 211-217.

33. Mayer MC, Breithaupt C, Reindl M, et al. Distinction and temporal stability of conformational epitopes on myelin oligodendrocyte glycoprotein recognized by patients with different inflammatory central nervous system diseases. J Immunol 2013;191:3594-3604.

34. Dale RC, Tantsis E, Merheb V, et al. Antibodies to MOG have a demyelination phenotype and affect oligodendrocyte cytoskeleton. Neurol Neuroimmunol Neuroinflamm 2014;1:e12; doi: 10.1212/NXI.0000000000000012.

35. Beck RW, Trobe JD, Moke PS, et al. High- and low-risk profiles for the development of multiple sclerosis within 10 years after optic neuritis: experience of the optic neuritis treatment trial. Arch Ophthalmol 2003;121:944-949.

36. Kidd D, Burton B, Plant GT, Graham EM. Chronic relapsing inflammatory optic neuropathy (CRION). Brain 2003;126:276-284. 
37. Petzold A, Plant GT. Chronic relapsing inflammatory optic neuropathy: a systematic review of 122 cases reported. J Neurol 2014;261:17-26.

38. Waters P, Woodhall M, Hacohen Y, et al. Antibodies to myelin oligodendrocyte glycoprotein (MOG) in children and adults with demyelinating disorders (NMO). Ann Neurol 2013;74:S18-S19.
39. Kezuka T, Usui Y, Yamakawa N, et al. Relationship between NMO-antibody and anti-MOG antibody in optic neuritis. J Neuroophthalmol 2012;32:107-110.

40. Kezuka T, Tanaka K, Matsunaga Y, et al. Distinction between MOG antibody-positive and AQP4 antibodypositive NMO spectrum disorders. Neurology 2014;83: 475-476. 


\section{Neurology \\ Neuroimmunology \& Neuroinflammation}

\section{Antibodies to myelin oligodendrocyte glycoprotein in bilateral and recurrent optic neuritis \\ Sudarshini Ramanathan, Stephen W. Reddel, Andrew Henderson, et al. \\ Neurol Neuroimmunol Neuroinflamm 2014;1; \\ DOI 10.1212/NXI.0000000000000040}

This information is current as of October 29, 2014

Updated Information \&
Services
Supplementary Material
References
Citations
Permissions \& Licensing
Reprints

Updated Information \&

Reprints including high resolution figures, can be found at:

http://nn.neurology.org/content/1/4/e40.full.html

Supplementary material can be found at:

http://nn.neurology.org/content/suppl/2014/10/29/1.4.e40.DC1

This article cites 40 articles, 6 of which you can access for free at: http://nn.neurology.org/content/1/4/e40.full.html\#\#ref-list-1

This article has been cited by 5 HighWire-hosted articles: http://nn.neurology.org/content/1/4/e40.full.html\#\#otherarticles

Information about reproducing this article in parts (figures,tables) or in its entirety can be found online at:

http://nn.neurology.org/misc/about.xhtml\#permissions

Information about ordering reprints can be found online:

http://nn.neurology.org/misc/addir.xhtml\#reprintsus

Neurol Neuroimmunol Neuroinflamm is an official journal of the American Academy of Neurology.

Published since April 2014, it is an open-access, online-only, continuous publication journal. Copyright $\odot$ 2014 American Academy of Neurology. All rights reserved. Online ISSN: 2332-7812.

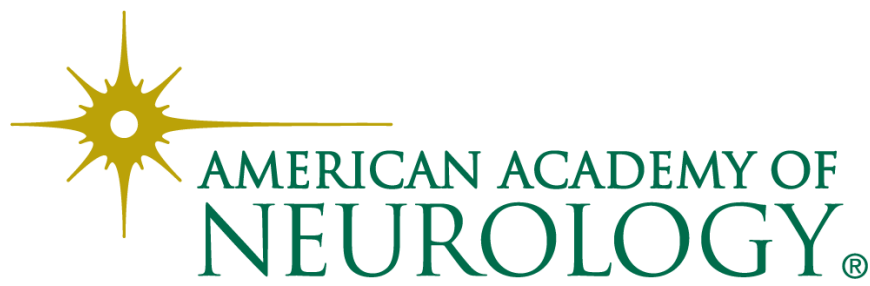

